\title{
Perancangan Hybrid Mobile Application Penghubung Orang tua dan Guru pada Sekolah Taman Kanak-Kanak
}

\author{
Charlene Alicia Wagiu ${ }^{1}$, Yulianus Palopak ${ }^{2}$ \\ 1,2Fakultas Teknologi Informasi, Universitas Advent Indonesia \\ e-mail: ${ }^{1}$ charlene.wagiu@unai.edu, ${ }^{2}$ ypalopak@unai.edu
}

\begin{abstract}
Abstrak
Orang tua dan guru merupakan sosok utama dalam pendidikan anak usia sekolah. Di sekolah, guru yang berperan dalam mendidik siswa, namun di luar sekolah orang tualah yang bertanggungjawab dalam mendidik anaknya. Oleh sebab itu komunikasi antara orang tua siswa dan guru merupakan hal yang sangat penting. Pada kenyataannya, banyak hal yang menjadi penghalang dalam komunikasi antara guru dan orang tua siswa. Kesibukan dan keterbatasan waktu menjadi salah satu penghalang yang paling besar. Dibutuhkan adanya sebuah sistem yang dapat memfasilitasi guru dan orang tua siswa, sehingga komunikasi antara guru dan orang tua siswa dapat berjalan dengan lancar dan proses belajar mengajar dapat berjalan dengan baik. Penelitian ini membangun sebuah aplikasi yang bertujuan untuk memfasilitasi komunikasi antara guru dan orang tua siswa dengan menggunakan teknologi mobile hybrid. Teknologi mobile hybrid dipilih karena dapat menjadi solusi untuk pengembangan aplikasi yang dapat digunakan pada berbagai platform yang tersedia pada smartphone seperti Android, ios dan Windows. Metode yang digunakan dalam pengembangan sistem ini adalah SDLC (System Development Life Cycle) dengan model waterfall dengan tahapan-tahapan analisis, perancangan, implementasi dan pemeliharaan sistem. Hasil perancangan ini berupa sebuah aplikasi yang dapat digunakan pada berbagai platform smartphone, yang dapat memfasilitasi komunikasi antara guru dan orang tua siswa.
\end{abstract}

Kata-kata kunci: Mobile hybrid, aplikasi sekolah

\section{Design of Hybrid Mobile Application for Parents and Teachers in Kindergarten Schools}

\begin{abstract}
Parents and teachers are the main figures in the education of school-age children. In school, teachers play a role in educating students, but outside of school parents are responsible to nurture their children. Therefore communication between parents and teachers is very important. In fact, there are many barriers in communication between teachers and parents. Busyness and time limitedness are the biggest problem. There is a need for a system that can facilitate communication activity betweenteachers and parents. This research builds an application that facilitates communication between teachers and parents using hybrid mobile technology. Mobile hybrid technology was chosen because it can be a solution for application development that can be used on various platforms available on smartphones such as Android, iOS and Windows. The method used in the development of this system is SDLC (System Development Life Cycle) with the waterfall model with the stages of analysis, design, implementation and maintenance of the system. The results of this design are in the form of an application that can be used on various smartphone platforms, which can facilitate communication activity between teachers and parents.
\end{abstract}

Key words: Hybrid mobile, school application 


\section{Pendahuluan}

Taman kanak-kanak merupakan jenjang pendidikan anak usia dini (biasanya dibawah 6 tahun), yang bertujuan untuk membentuk pola pikir anak dengan cara bermain sambil belajar juga mempersiapkan anak agar siap untuk memasuki jenjang pendidikan lebih lanjut. Proses belajar mengajar yang terjadi tak bisa lepas dari peran guru dan orang tua. Di sekolah, gurulah yang menjadi orang tua siswa, tetapi begitu siswa keluar dari sekolah orang tualah yang mempunyai peranan penting dalam mendidik anaknya. Pada dasarnya, orang tua dan guru memiliki kewajiban yang sama dalam pendidikan anak, yaitu memastikan siswa/anak mendapatkan pendidikan yang baik. Oleh karena itu dibutuhkan kolaborasi antara guru dan orang tua siswa yang bertujuan agar pendidikan dan perkembangan anak/siswa dapat optimal dan sesuai dengan yang diharapkan. Salah satu bentuk kolaborasi antara orang tua siswa dan guru adalah komunikasi.

Terdapat tiga alasan pentingnya komunikasi yang efektif antara guru dengan orang tua. Pertama, guru harus mengetahui semua kebutuhan dan harapan anak maupun orang tua. Kedua, orang tua memerlukan informasi yang jelas tentang hal-hal di sekolah (program, pelaksanaan, dan peraturan yang berlaku di sekolah). Ketiga, komunikasi yang baik antara guru dan orang tua akan membantu proses pendidikan yang baik [3]. Selain hal-hal yang telah disebutkan diatas, orang tua siswa juga selalu ingin mengetahui nilai-nilai yang didapatkan sang anak, jumlah kehadiran, jadwal pelajaran dan berharap dapat berkomunikasi secara intens dengan guru sekolah.

Pada kenyataannya banyak faktor yang dapat menghambat komunikasi antara guru dan orang tua siswa, seperti keterbatasan waktu dan prioritas. Kesibukan guru maupun orang tua membuat komunikasi antara kedua belah pihak sulit dilakukan. Dalam berkomunikasi dengan orang tua siswa, pada umumnya pihak sekolah masih menggunakan cara-cara konvensional, contohnya melalui surat pengumuman yang diberikan kepada siswa untuk diberikan kepada orang tua, ataupun secara lisan. Pengumuman tersebut contohnya berisi informasi hari libur sekolah, jadwal ujian sekolah, peralatan yang harus dibawa untuk praktek pelajaran, dan yang lainnya. Tentunya cara-cara seperti ini dapat menimbulkan masalah. Jika siswa menghilangkan surat yang dititipkan pihak sekolah atau lupa memberikanya kepada orang tua, maka pesan yang dimaksudkan tidak akan tersampaikan kepada orang tua siswa. Hambatan-hambatan komunikasi seperti ini dapat menyebabkan timbulnya konflik pada masa mendatang, hal ini tentu saja akan merugikan semua pihak dan akan berdampak langsung kepada si anak/siswa, konsentrasi belajar anak/siswa akan terganggu.

Berdasarkan latar belakang yang telah dijelaskan, maka dibutuhkan suatu sistem yang dapat menghubungkan guru dan orang tua siswa. Di jaman serba teknologi saat ini, solusi yang terbaik adalah dengan tersedianya aplikasi khusus untuk memfasilitasi guru dan orang tua siswa. Saat ini hampir semua lapisan masyarakat telah menggunakan alat komunikasi smartphone. IBM pada situs resminya mengatakan bahwa dari 7 triliun populasi di dunia, 6 triliun memiliki mobile phone. Hal inilah yang menggeser perkembangan teknologi dari yang sebelumnya dikembangkan berbasis web kini lebih diutamakan pengembangan aplikasi berbasis mobile. Namun berbagai macam platform dalam smartphone menjadi tantangan baru untuk mengembangkan sebuah aplikasi.

Terdapat tiga pendekatan yang dapat digunakan dalam pengembangan aplikasi mobile yaitu native application, web application dan hybrid application. Native application merupakan aplikasi yang khusus dikembangkan untuk platform tertentu dan menggunakan bahasa pemrograman serta perangkat lunak yang sesuai dengan platform yang dimaksud. Web application merupakan aplikasi versi web yang juga dapat diakses melalui perangkat mobile. Sedangkan hybrid application merupakan perpaduan dari native application dan web application sehingga aplikasi ini dapat digunakan pada beberapa platform yang berbeda [1]. Hybrid application merupakan teknologi menggabungkan aplikasi native dan teknologi web, hal ini membuat programmer dapat mengembangkan aplikasi mobile dengan bahasa dasar PHP, HTML, CSS, dan JavaScript [5].

Penelitian ini adalah pengembangan aplikasi sistem komunikasi yang memadukan pada kedua pengembangan aplikasi yang telah dikembangkan yaitu dengan membuat aplikasi penghubung guru dan orang tua siswa dengan menggunakan aplikasi hybrid. Aplikasi penghubung ini akan dapat digunakan pada 
beberapa platform yaitu android, windows dan iOS. Aplikasi ini juga akan dapat digunakan penunjang proses penghubung antara guru dan orang tua siswa baik secara online maupun offline, dan terhubung dengan sistem admin yang berbasis web.

\section{Hybrid Application}

Hybrid application adalah teknologi menggabungkan dua bahasa pemrograman atau dua teknologi menjadi satu, yang membuat perkerjaan developer lebih ringan dalam proses pengembangan aplikasinya ke segala jenis sistem operasi smartphone [5]. Menurut Tun [4], hybrid application menggabungkan native application dan teknologi web. Dengan menggunakan hybrid application, programmer dapat membuat mobile application dengan mengandalkan kemampuan web progamming.

Kerangka (framework) untuk pengembangan hybrid application dipisahkan menjadi dua jenis, yaitu antarmuka pemakai dan pengemasan aplikasi menjadi platform yang berbeda dan memungkinkan untuk mengakses fitur smartphone [2]. Dengan kata lain, aplikasi mobile hybrid dapat berjalan pada beberapa platform seperti Android, iOS, Windows Phone, dan platform lain yang mendukung HTML5 browser karena berjalan pada komponen WebView yang dimiliki oleh platform tersebut.

Mobile hybrid application dipilih dalam teknik pembuatan aplikasi antar platform karena sifatnya yang sekali coding dapat digunakan dalam beberapa platform yang berbeda.

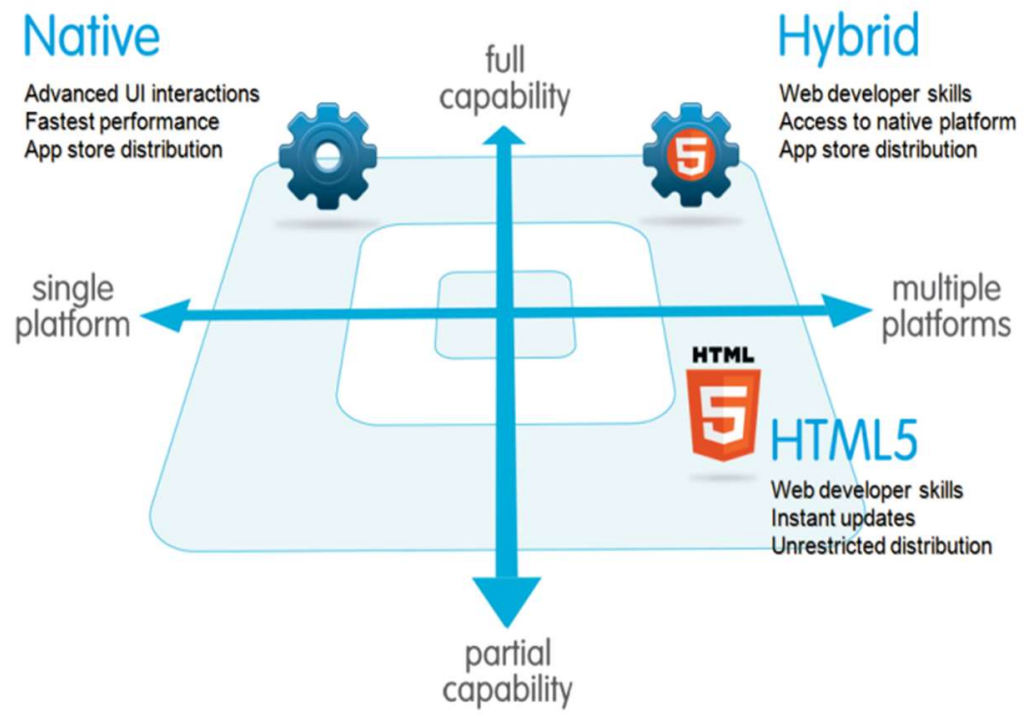

Gambar 1 Perbandingan Native dan Hybrid Application [2]

\section{Ionic Framework}

Ionic adalah kerangka ponsel HTML5 dengan fokus pada kinerja yang memanfaatkan akselerasi hardware dan tidak memerlukan pihak ketiga seperti JavaScript library. Ionic bekerja bersama-sama dengan Angular]s untuk membangun user interface aplikasi yang interaktif hanya dengan satu halaman. Aplikasi yang menggunakan Ionic biasa disebut aplikasi hybrid, yang pada dasarnya ialah website kecil yang berjalan di shell browser yaitu sebuah aplikasi yang memiliki akses ke lapisan platform asli dari sebuah device. Aplikasi hybridmemiliki banyak manfaat jika dibandingkan dengan aplikasi native, khususnya dalam hal mendukung platform dan kecepatan pengembangan [7]. 


\section{Apache Cordova}

Apache Cordova adalah framework open source untuk pengembangan aplikasi mobile tanpa menggunakan bahasa pemrograman native pada platform mobile. Aplikasi dieksekusi menggunakan standart API yang tersedia untuk mengakses data, device sensor atau status jaringan pada device. Apache cordova dapat digunakan untuk mengembangkan aplikasi pada beberapa platform, pengembangan web yang didistribusikan kedalam mobile device dan menggabungkan komponen aplikasi bahasa pemrograman native dengan WebView yang dapat mengakses API pada perangkat mobile [8].

\section{Perancangan Sistem}

Perancangan sistem dilakukan untuk menggambarkan suatu model aplikasi yang akan digunakan dalam pengembangan sistem. Metode penelitian yang digunakan dalam penelitian ini adalah metode deskriptif kualitatif. Dalam prosesnya, tahapan dimulai dengan mengamati objek yang terkait, analisis kebutuhan pengguna dan pengumpulan data.

Tahap berikutnya adalah desain sistem. Dari Use Case Diagram berikut ini dapat dilihat apa saja yang dapat dilakukan oleh sistem yang akan dibangun.

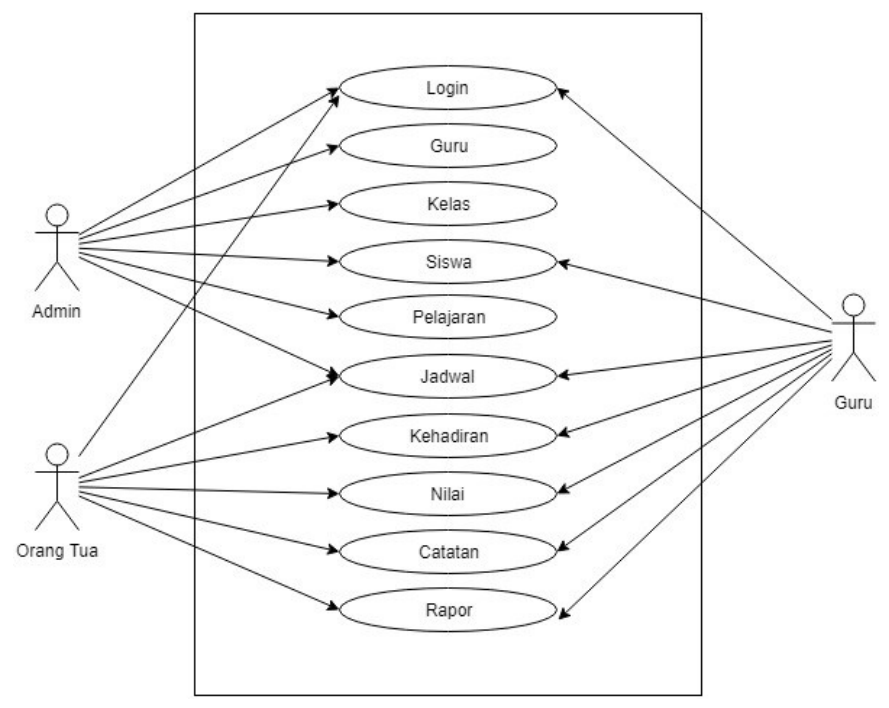

Gambar 2 Use Case Diagram

\section{Tampilan Antarmuka Pengguna}

Antarmuka pengguna merupakan suatu sarana interaksi antara pengguna dengan aplikasi. Tampilan aplikasi sangat berpengaruh terhadap kemudahan seluruh user dalam menggunakan aplikasi ini, oleh sebab itu aplikasi ini dibuat semudah mungkin agar mudah dipahami dan digunakan oleh user. Berikut ini adalah penjelasan tampilan-tampilan antarmuka yang telah dirancang.

Setelah melakukan proses login, aplikasi akan menampilkan menu utama yang terdiri dari menu Siswa, Absensi, Catatan dan Rapor. Pada tampilan menu Siswa ini, guru dapat memilih kelas yang ada dan dapat melihat daftar nama-nama siswa yang ada pada kelas tersebut. Guru juga dapat melihat data siswa secara detail. 


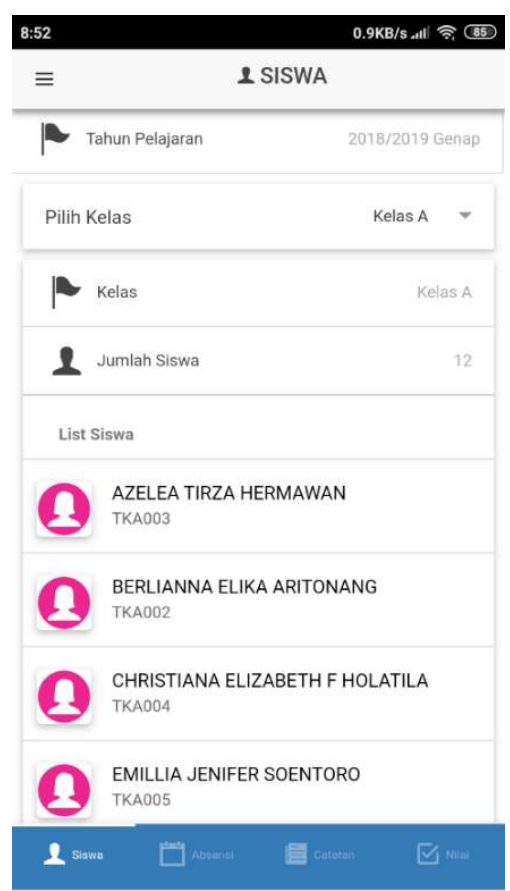

Gambar 3 Antarmuka Daftar Siswa

Gambar 4 dan 5 di bawah ini menunjukkan tampilan antarmuka Absensi. Pada menu ini, guru dapat melakukan absensi harian kepada siswa kelasnya. Data absensi dapat dilihat secara tanggal ataupun secara siswa.

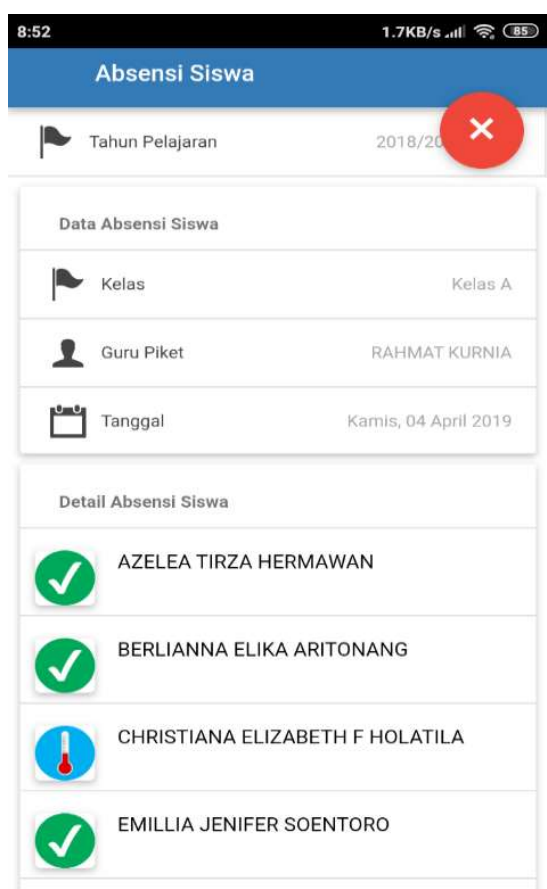

Gambar 4 Antarmuka Data Absensi Berdasarkan Siswa

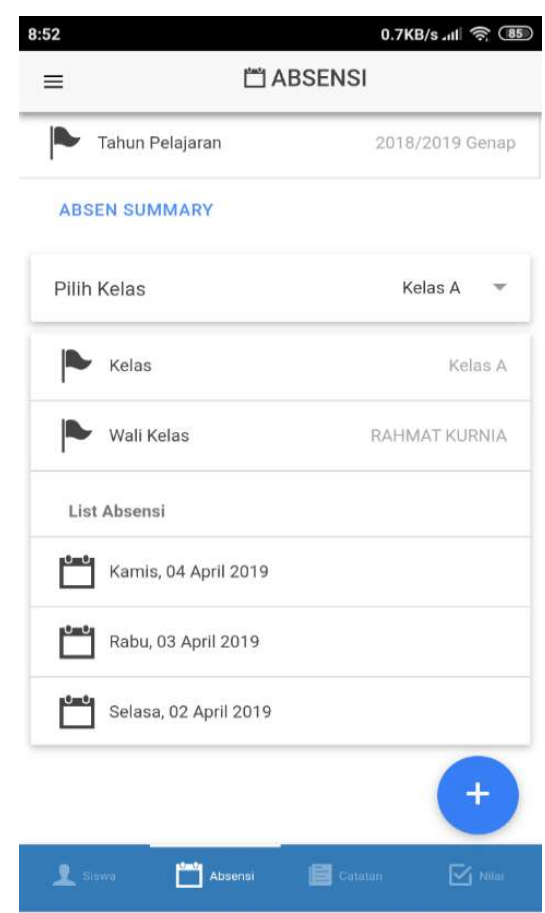

Gambar 5 Antarmuka Data Absensi Berdasarkan Tanggal 
Pada Gambar 6 di bawah ini ditampilkan antarmuka menu Catatan Siswa. Guru dapat memberikan catatan kepada orang tua untuk siswa yang bersangkutan kapan pun diperlukan. Catatan ini dapat merupakan pengumuman, laporan perilaku siswa di sekolah, jadwal ujian dan yang lainnya.

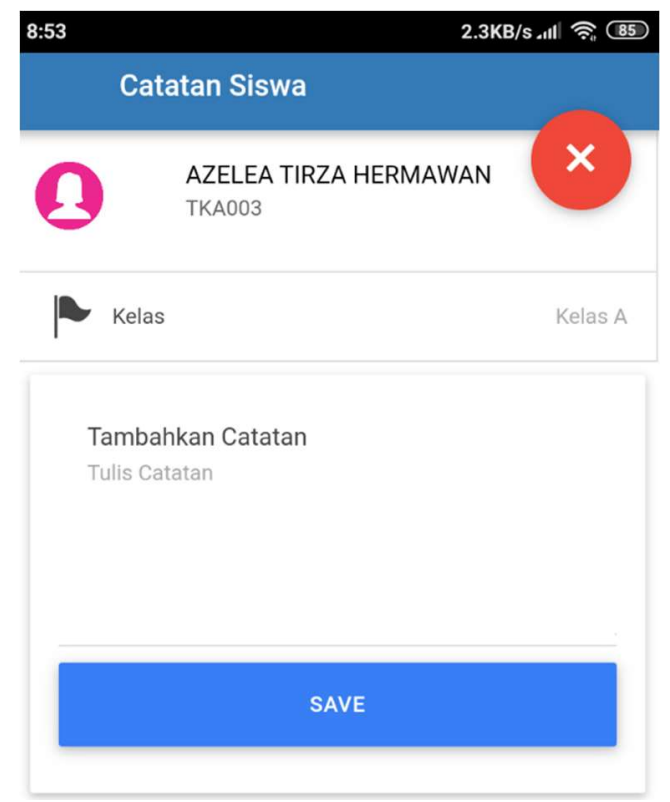

Gambar 6 Antarmuka Catatan Siswa

Melalui aplikasi ini, guru dapat mengisi rapor seluruh siswa yang ada pada menu Rapor (Gambar 7). Setelah selesai melakukan pengisian rapor, maka rapor akan disimpan dan dapat dilihat melalui tampilan antarmuka Rapor (Gambar 8).

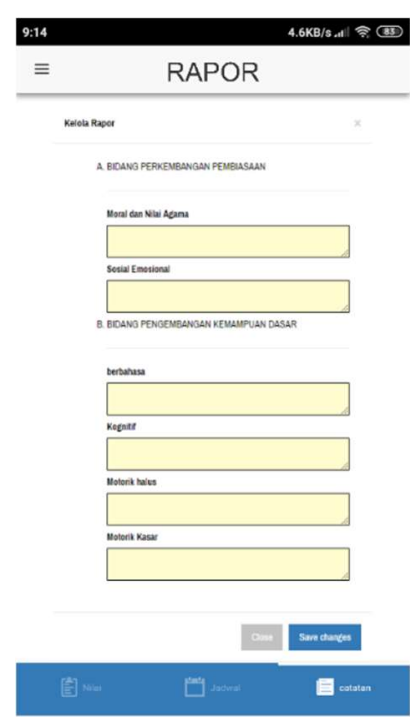

Gambar 7 Antarmuka Pengisian Rapor

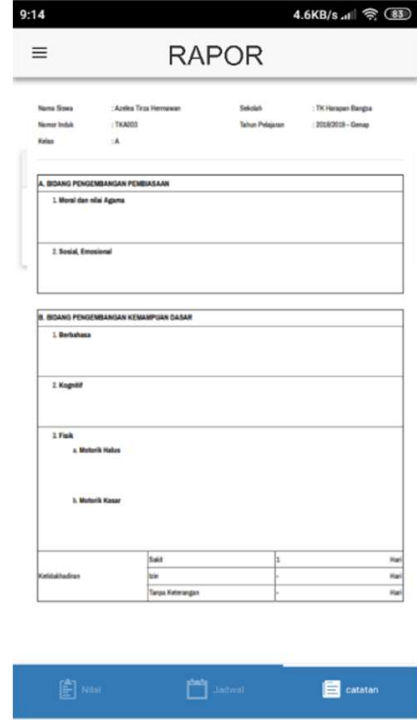

Gambar 8 Antarmuka Tampilan Rapor Sisw

Berikut ini ditampilkan antarmuka-antarmuka dengan user orang tua siswa. Setelah melakukan aktivitas login, orang tua dapat memilih menu-menu yang disediakan, salah satunya adalah menu profil siswa. Orang tua siswa hanya dapat melihat profil anaknya, yang terdiri dari data lengkap pribadi dari siswa yang bersangkutan. 
Menu lainnya yang ada pada akun orang tua adalah absensi siswa. Orang tua dapat melihat data absensi harian anaknya dan juga rangkuman absensi per bulan dan per semester beserta keterangan lengkapnya. Menu absensi dapat dilihat pada Gambar 11.

Pada Gambar 12 di bawah ini ditampilkan menu jadwal pelajaran siswa. Orang tua dapat melihat jadwal harian pelajaran anak mereka.

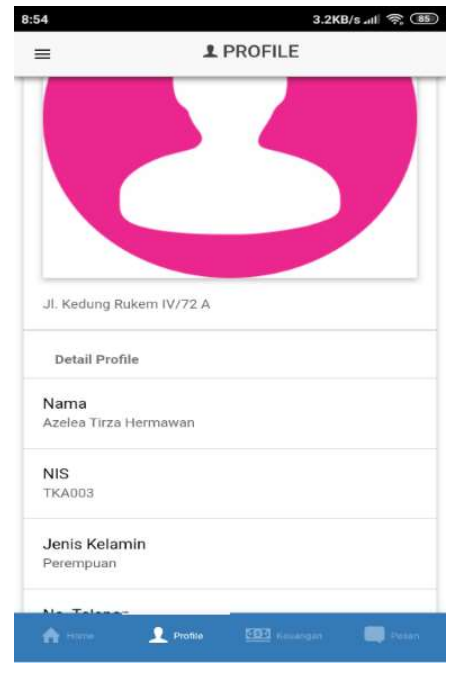

Gambar 10 Antarmuka Profil Siswa

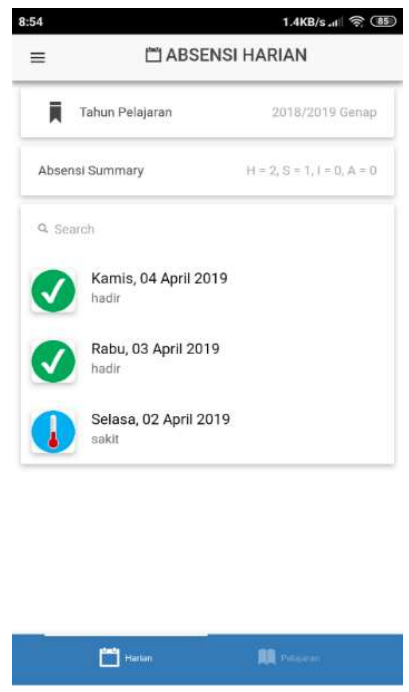

Gambar 11 Antarmuka Absensi Harian

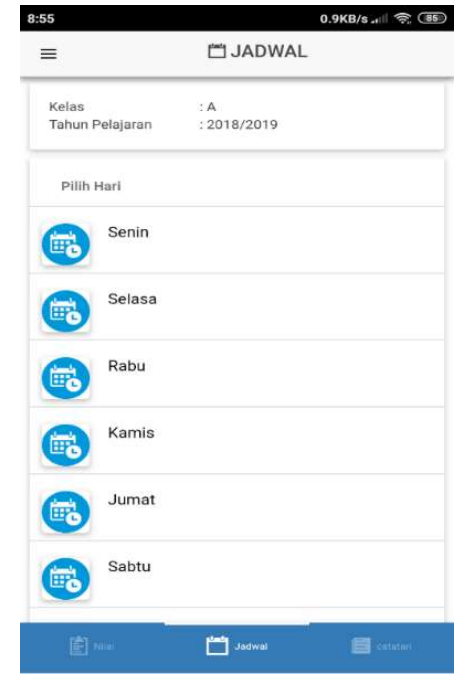

Gambar 12 Antarmuka Jadwal Pelajaran Siswa

Menu berikutnya yang terdapat dalam akun orang tua siswa adalah menu catatan. Menu catatan ini menampilkan catatan-catatan yang diberikan oleh guru untuk orang tua ataupun sebaliknya. Melalui menu inilah guru dan orang tua dapat saling berkomunikasi dua arah dan hanya dapat dibaca oleh yang bersangkutan. Menu catatan ini ditampilkan pada Gambar 13.
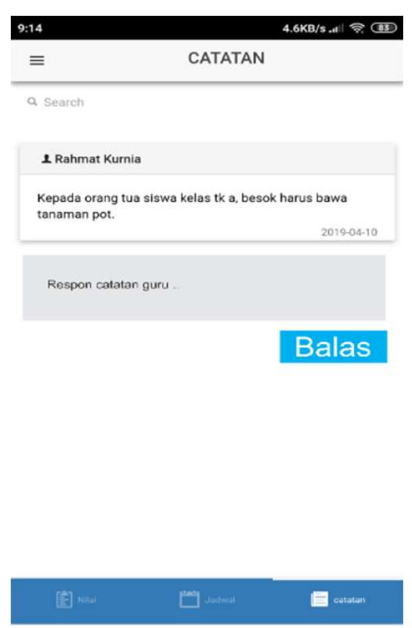

Gambar 13 Antarmuka Tampilan Menu Catatan

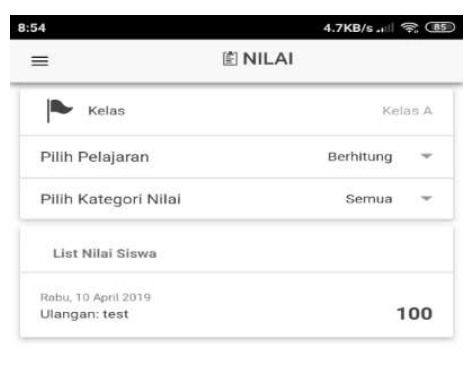

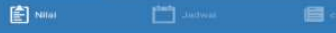

Gambar 14 Antarmuka Nilai Siswa
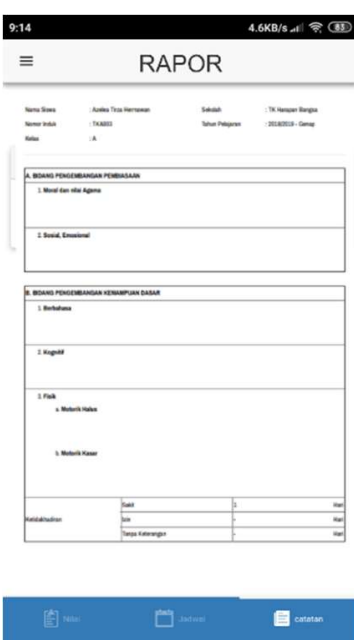

Gambar 15 Antarmuka Tampilan Rapor Siswa

Gambar 14 menampilkan menu nilai siswa. Orang tua dapat melihat semua nilai pelajaran anaknya berdasarkan mata pelajaran yang dipilih. Menu Rapor pada Gambar 15 adalah menu yang ditampilkan pada 
akun orang tua siswa. Dengan adanya menu ini, orang tua tidak harus datang ke sekolah untuk mengambil rapor si anak karena orang tua dapat melihat rapor masing-masing anak melalui aplikasi ini.

\section{Kesimpulan}

Berdasarkan hasil penelitian dengan merancang dan membangun aplikasi penghubung antara guru dan orang tua, maka didapatkan kesimpulan bahwa aplikasi penghubung antara guru dan orang tua ini dapat membantu memfasilitasi komunikasi antara guru dan orang tua siswa. Dengan menggunakan fasilitas menu yang terdapat pada aplikasi ini, masing-masing guru dan orang tua mendapatkan kemudahan, guru dapat dengan mudah memberikan informasi kepada orang tua berkaitan dengan kegiatan dan hasil belajar siswa dan orang tua dapat dengan mudah mendapatkan informasi detail mengenai anak mereka, mulai dari informasi absensi/kehadiran, catatan khusus, pengumuman, informasi nilai harian sampai dengan rapor.

\section{Referensi}

[1] Hasan, Y., Zaidi, M., Haider, N., Hasan, W.U dan Amin, I., 2012, Smartphones Application Development Using HTML5 and Related Technologies: A Tradeoff between Cost and Quality, Int. Journal of Computer Science Issue, 9, 3, 455-461

[2] R. Gangundi, Smartphone Application Development using Cross Platform Frameworks, in Proceedings of the National Conference on Information and Communication Technology, NMIMS University, Mumbai, India, 2010.

[3] Soemarti Padmonodewo. (2003). Pendidikan Anak Prasekolah. Jakarta: PT.Rineka Cipta

[4] Tun, Phyo Min. 2014. Choosing a Mobile Application Development Approach. Stamford International University, Thailand

[5] V. Noer Firdausy, F. Agus, I. Fitri Astuti, Aplikasi Android Hybrid Untuk Pemilihan Lokasi Kuliner, Universitas Mulawarman, 2017

[6] Wargo, J. (2012). PhoneGap Essential:Building Cross-platform Mobile Apps. United States: AddisonWesley Professional

[7] https://cordova.apache.org

[8] http://ionicframework.com/ 